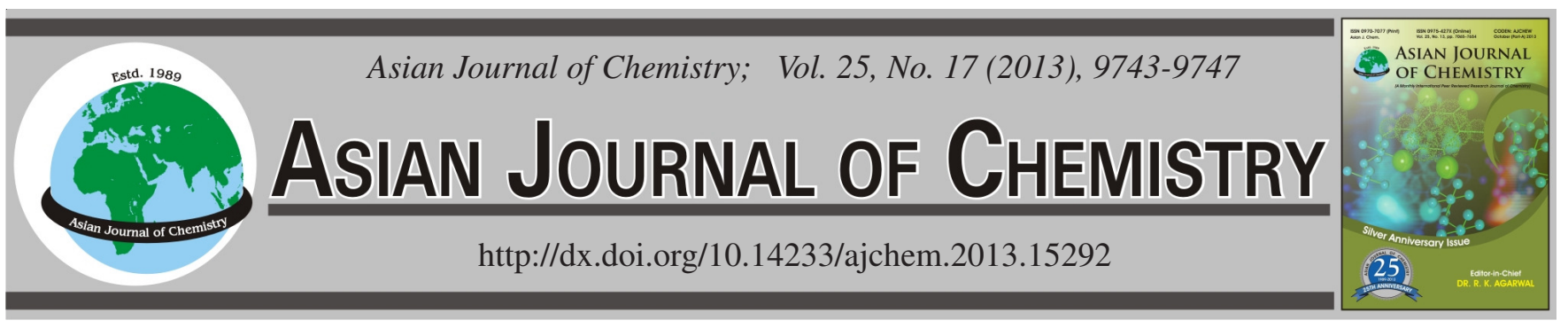

\title{
Effect of Inhibitors on Corrosion Control of Mild Steel in Natural Aqueous Environment
}

\author{
V. Manivannan ${ }^{1, *}$ and N. Chithralekha ${ }^{2}$
}

${ }^{1}$ Department of Chemistry, Paavai College of Engineering, Namakkal-637 018, India

${ }^{2}$ Department of Physics, Mahendra College of Engineering, Salem-636 106, India

*Corresponding author: E-mail: manivannanv1971@gmail.com

(Received: 6 February 2013;

Accepted: 18 October 2013)

AJC-14266

Corrosion inhibition by new triazole derivatives, 2-phosphonoacetic acid (2-PAA) and $\mathrm{Zn}^{2+}$ on mild steel in aqueous media has been
investigated by weight loss and potentiodynamic polarization, electrochemical impedance spectroscopy and atomic absorption spectroscopic
methods. The results indicate that these compounds act as mixed-type inhibitors retarding the anodic and cathodic corrosion reactions.
Combination of 1-(2-pyrrolecarbonyl)benzotriazole along with $\mathrm{Zn}^{2+}$ and 2-phosphonoacetic acid shows better corrosion inhibition efficiency
than other inhibitor combinations and the individual inhibitors.

\section{INTRODUCTION}

Chloride, sulphate and nitrate ions in aqueous media are particularly aggressive to mild steel and accelerate its corrosion. The service life of steel is enhanced by various corrosion control methods based on modifying either the surface of the metal or the local environment to which the metal is exposed. Mild steel is a common constructional material for many industrial units because of its cost and excellent mechanical properties. However, it suffers severe attack in service, particularly in oil and gas production systems ${ }^{1}$. Corrosion of steel is effectively controlled by the application of suitable inhibitors ${ }^{2}$. The majority of the well-known corrosion inhibitors are compounds containing nitrogen, oxygen, phosphorus and sulphur in their functional groups with aromatic and heterocyclic rings $s^{3-12}$. Most of these organic compounds are adsorbed on the metal surface and provide a barrier between metal and environment, thereby reducing the rate of corrosion. The effectiveness of inhibition depends on the nature and surface charge of the metal, the nature of the medium, the nature and chemical structure of the inhibitor molecule such as functional groups, aromaticity, the $\pi$ orbital character of the donating electron, steric factor and electron density at the donor atoms ${ }^{13-16}$. In view of the excellent performance of triazole-type organic compounds, we have synthesized an environmentally acceptable multi-component inhibitors (triazole based) bearing phenyl, azomethine, phosphonate groups in the same molecule, with objective of evaluating its corrosion inhibition properties on mild steel in natural aqueous environment. We already studied that the inhibitive effect of 1-(2-pyrrolecarbonyl)benzotriazole, 1-(2-thienylcarbonyl)benzotriazole with $\mathrm{Zn}^{2+}$ and 4-phosphonobutyric acid.

In the present study, we reported that the inhibiting action of 1-(2-pyrrolecarbonyl)benzotriazole (PCBT), 1-(2thienylcarbonyl)benzotriazole (TCBT), benzotriazole (BTA) with $\mathrm{Zn}^{2+}$ and 2-phosphonoacetic acid (2-PAA).

\section{EXPERIMENTAL}

Synthesis of benzotriazole derivatives: Both the benzotriazole derivatives (TCBT and PCBT) were synthesized by adopting literature procedures ${ }^{17-19}$ and the products were characterized by FT-IR and NMR. The structures of the compounds under investigation are given in Fig. 1.

Specimen preparation: Specimens of mild steel with the composition C-0.13\%, P-0.032\%, Si-0.014\%, S-0.025\%, $\mathrm{Mn}-0.48 \%$ and balance Fe were used. For each electrochemical study, specimens of size $1.0 \mathrm{~cm} \times 1.0 \mathrm{~cm} \times 0.3 \mathrm{~cm}$ were cut, embedded in epoxy resin and mechanically polished with silicon carbide papers (from grades 120-1,200) followed by then washing with double distilled water, degreasing with acetone and drying at room temperature. For weight loss measurements metal specimens of $4 \mathrm{~cm} \times 2 \mathrm{~cm} \times 0.2 \mathrm{~cm}$ dimension were used. A sample that was more corrosive in nature was chosen as the test solution for all the experiments. The typical analysis of this electrolyte is given in Table-1.

Weight loss measurements: Mild steel specimens in triplicate were immersed in ground water at room temperature for each inhibitor concentration for 7 days. The specimens 


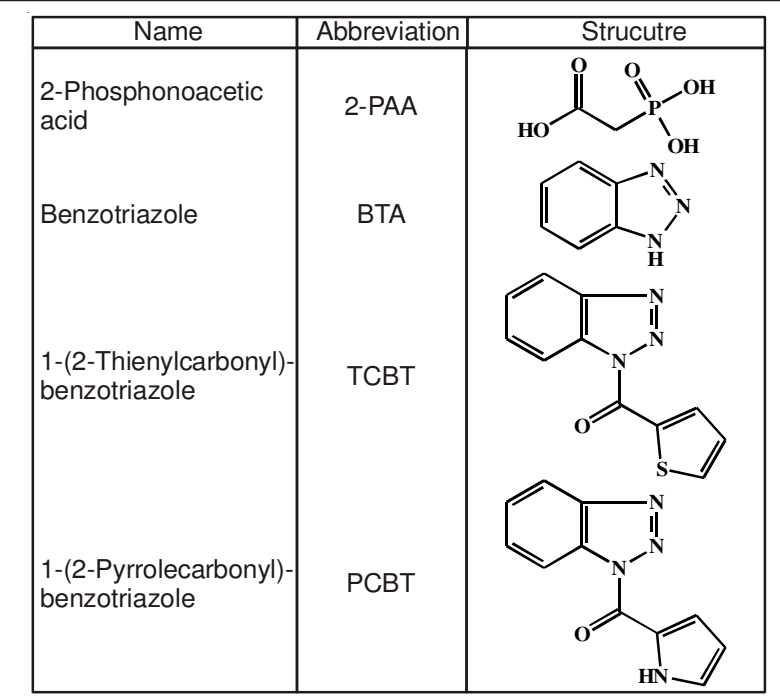

Fig. 1. Structures of the benzotriazole derivatives and phosphonic acid derivative

TABLE-1

ANALYSIS OF GROUND WATER (ELECTROLYTE)

\begin{tabular}{|c|c|c|c|}
\hline Parameter & Value & Parameter & Value \\
\hline $\mathrm{pH}$ & 6.78 & TDS & $586 \mathrm{ppm}$ \\
\hline Temperature & $28^{\circ} \mathrm{C}$ & Langelier saturation index & -0.02 \\
\hline Total hardness & $332 \mathrm{ppm}$ & Ryznar stability index & 6.82 \\
\hline Alkalinity & $316 \mathrm{ppm}$ & - & - \\
\hline
\end{tabular}

were removed, rinsed in double distilled water and acetone then kept in a desiccator. Then the weight loss was determined in order to calculate the inhibition efficiency (IE) using the formula,

$$
\operatorname{IE}(\%)=\frac{\mathrm{W}_{\mathrm{o}}-\mathrm{W}_{\mathrm{i}}}{\mathrm{W}_{\mathrm{o}}} \times 100
$$

where, $\mathrm{W}_{0}$ and $\mathrm{W}_{\mathrm{i}}$ are the weight loss in the absence and presence of inhibitor, respectively.

Electrochemical studies: All the electrochemical measurements presented in this study were performed using the Electrochemical Workstation (Model No: CHI 760, CH Instruments, USA). Prior to the electrochemical measurements, the metal specimens were prepared according to the procedure described above. All the experiments were carried out at room temperature with ground water as an electrolyte. The platinum electrode and saturated calomel electrode (SCE) were used as auxiliary and reference electrodes, respectively and the working electrodes constitute mild steel specimens of $1 \mathrm{~cm}^{2}$ area. In order to minimize ohmic potential drop the tip of the reference electrode is positioned very close proximity to the working electrode surface by the use of fine Luggin capillary and the remaining uncompensated resistance was also reduced by electrochemical workstation. Potentiodynamic polarization curves were also obtained at different temperatures to observe the temperature dependence of inhibition effects.

Potentiodynamic polarization measurements: Potentiodynamic polarization studies were carried out at a scan rate of $0.1 \mathrm{mV} / \mathrm{s}$. In all cases the OCP was established first and then the polarization measurement was carried out. The polarization curves for mild steel specimens in the test solution with and without various concentrations of inhibitors were recorded from -1200 to $0 \mathrm{mV}$.
Electrochemical impedance studies: The electrochemical impedance studies were carried out in the same setup used for potentiodynamic polarization studies described above. The applied ac perturbation signal was about $10 \mathrm{mV}$ within the frequency range of $100 \mathrm{kHz}$ to $1 \mathrm{~Hz}$. All electrochemical impedance measurements were carried out at an open circuit potential.

Atomic absorption spectroscopic analysis: The concentration of iron present in the mild steel immersed in the ground water environment in the absence and presence of inhibitor was characterized by atomic absorption spectroscopy. The atomic absorption spectroscopy based on the absorption of light by atoms in the free atomic state can quantitatively fit the purpose. The amount of iron leached-out to the solution after carrying out potentiodynamic polarization measurement of mild steel in ground water in the absence and presence of inhibitors was estimated by AAS technique.

\section{RESULTS AND DISCUSSION}

Weight loss measurements: The corrosion rate and inhibition efficiency of all the inhibitors were tested for seven different concentrations was given in Table-2. There is a significant decrease in the corrosion rate with increase in concentration of each inhibitor and the extent of inhibition depends on the nature and concentration of the inhibitor. The optimum concentration was evaluated based on inhibition efficiency; for BTA, TCBT and PCBT, these are 18, 16 and 12 ppm, respectively. BTA, TCBT and PCBT have a maximum inhibition efficiency of 65.0, 70.7 and $74.4 \%$, respectively. Other individual inhibitors such as $\mathrm{Zn}^{2+}$ and 2-PAA showed a maximum inhibition efficiency of 67.7 and $61.9 \%$, respectively while the binary combination PCBT + 2-PAA had a inhibition efficiency of $78.3 \%$. Among all the individual, binary and ternary systems studied by weight loss method the ternary combination of PCBT $+\mathrm{Zn}^{2+}+2$-PAA system had shown the maximum inhibition efficiency up to $88.4 \%$ and the corrosion rate was found to be $0.76 \mathrm{mpy}$.

TABLE-2

CORROSION RATE OF MILD STEEL IN GROUND WATER IN THE PRESENCE AND ABSENCE OF OPTIMUM CONCENTRATION OF THE VARIOUS INHIBITORS-WEIGHT LOSS MEASUREMENT

\begin{tabular}{lccc}
\hline \multicolumn{1}{c}{ Inhibitor } & $\begin{array}{c}\text { Inhibitor } \\
\text { conc. }(\mathrm{ppm})\end{array}$ & $\begin{array}{c}\text { Corrosion } \\
\text { rate }(\mathrm{mpy})\end{array}$ & $\begin{array}{c}\text { Inhibition } \\
\text { efficiency }(\%)\end{array}$ \\
\hline Blank & - & 6.6 & - \\
BTA & 18 & 2.3 & 65.0 \\
TCBT & 16 & 1.9 & 70.7 \\
PCBT & 12 & 1.7 & 74.4 \\
2-PAA & 12 & 2.51 & 61.96 \\
$\mathrm{Zn}^{2+}$ & 75 & 2.1 & 67.7 \\
$\mathrm{BTA}+2$-PAA & $18+12$ & 1.85 & 71.96 \\
TCBT + 2-PAA & $16+12$ & 1.56 & 74.30 \\
PCBT + 2-PAA & $12+12$ & 1.44 & 78.3 \\
BTA+Zn +2 -PAA & $18+75+12$ & 1.22 & 81.50 \\
TCBT $+\mathrm{Zn}^{2+}+2$-PAA & $16+75+12$ & 1.19 & 81.9 \\
PCBT $+\mathrm{Zn}^{2+}+2$-PAA & $12+75+12$ & 0.76 & 88.40 \\
\hline
\end{tabular}

Potentiodynamic polarization studies: From the corresponding polarization curves presented in Figs. 2 and 3, the corrosion potential shows a clear tendency to be more negative 


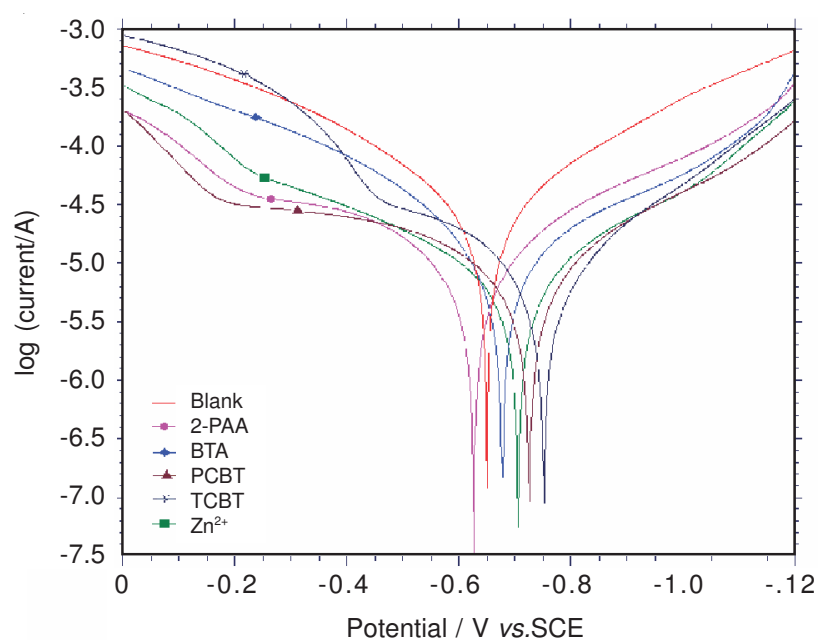

Fig. 2. Potentiodynamic polarization curves of mild steel in groundwater in the presence and absence of optimum concentration of 2-PAA, BTA, TCBT, PCBT and $\mathrm{Zn}^{2+}$

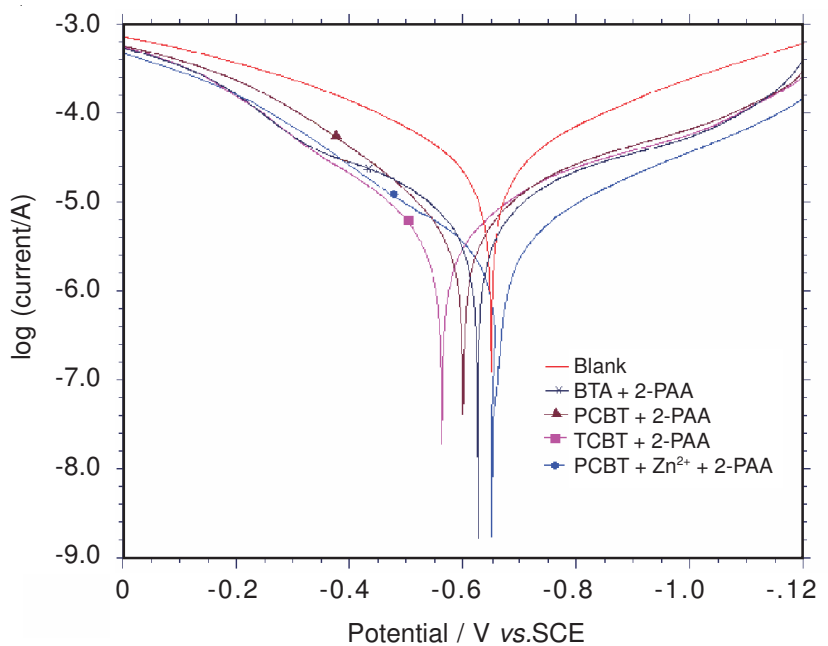

Fig. 3. Potentiodynamic polarization curves of mild steel in ground water in the presence and absence of optimum concentration of BTA + 2$\mathrm{PAA}, \mathrm{TCBT}+2-\mathrm{PAA}, \mathrm{PCBT}+2-\mathrm{PAA}$ and $\mathrm{PCBT}+\mathrm{Zn}^{2+}+2-\mathrm{PAA}$

for all the individual inhibitors except 2-PAA for which the shift in the $\mathrm{E}_{\text {corr }}$ value is positive. The electrochemical parameters of mild steel immersed in ground water for all the inhibitor systems are given in Tables 3 and 4. The corrosion potential in the presence of benzotriazole derivatives and $\mathrm{Zn}^{2+}$ shows a shift in the negative direction when compared with its absence. This shift demonstrates the cathodic inhibiting effect of the combination of both the benzotriazole derivatives with $\mathrm{Zn}^{2+}$. This confirms that the combination of benzotriazole compounds, $\mathrm{Zn}^{2+}$ and 2-PAA provides enhanced corrosion inhibition.

Electrochemical impedance studies: Impedance measurements of the mild steel electrode at its open circuit potential after $1 \mathrm{~h}$ of immersion in ground water alone and in the presence of various optimum inhibitor combinations were performed over the frequency range from $100 \mathrm{kHz}$ to $1 \mathrm{~Hz}$. Typical Nyquist plots obtained in the absence and presence of optimum inhibitor concentration simple, binary and ternary systems are shown in Figs. 4 and 5. The impedance diagrams obtained are not perfect semicircles and this difference has been attributed to frequency dispersion ${ }^{20}$. The values of the

\begin{tabular}{|c|c|c|c|c|c|}
\hline \multicolumn{6}{|c|}{$\begin{array}{c}\text { TABLE-3 } \\
\text { POTENTIODYNAMIC POLARIZATION PARAMETERS OF } \\
\text { MILD STEEL IN GROUND WATER IN THE ABSENCE } \\
\text { AND PRESENCE OF VARIOUS CONCENTRATIONS OF } \\
\text { BENZOTRIAZOLE DERIVATIVES, 2-PAA AND Zn }{ }^{2+} \mathrm{AT} 30^{\circ} \mathrm{C} \\
\end{array}$} \\
\hline Inhibitor & $\begin{array}{l}\text { Inhibitor } \\
\text { conc. } \\
\text { (ppm) }\end{array}$ & $\begin{array}{l}E_{\text {corr }} \\
(\mathrm{mV})\end{array}$ & $\begin{array}{c}\mathrm{i}_{\text {corr }} \\
\left(\mu \mathrm{Acm}^{-2}\right)\end{array}$ & $\begin{array}{l}\text { Corrosion } \\
\text { rate } \\
(\mathrm{mpy})\end{array}$ & $\begin{array}{c}\text { Inhibition } \\
\text { efficiency } \\
(\%)\end{array}$ \\
\hline Blank & - & -640 & 12.59 & 5.75 & - \\
\hline \multirow{7}{*}{ 2-PAA } & 6 & -669 & 7.23 & 3.30 & 42.5 \\
\hline & 8 & -744 & 6.38 & 2.91 & 49.3 \\
\hline & 10 & -681 & 5.15 & 2.35 & 59.0 \\
\hline & 12 & -627 & 4.71 & 2.15 & 62.6 \\
\hline & 14 & -714 & 6.07 & 2.77 & 57.7 \\
\hline & 16 & -713 & 6.42 & 2.93 & 49.0 \\
\hline & 18 & -684 & 7.50 & 3.42 & 40.4 \\
\hline \multirow{7}{*}{ BTA } & 12 & -662 & 6.30 & 2.87 & 50.0 \\
\hline & 14 & -650 & 5.25 & 2.39 & 58.3 \\
\hline & 16 & -673 & 4.78 & 2.18 & 62.0 \\
\hline & 18 & -680 & 4.36 & 1.99 & 65.4 \\
\hline & 20 & -676 & 4.47 & 2.04 & 64.5 \\
\hline & 22 & -690 & 5.01 & 2.29 & 60.2 \\
\hline & 24 & -672 & 5.62 & 2.56 & 55.4 \\
\hline \multirow{7}{*}{ TCBT } & 10 & -795 & 7.41 & 3.38 & 41.1 \\
\hline & 12 & -744 & 6.12 & 2.79 & 51.4 \\
\hline & 14 & -740 & 4.38 & 2.00 & 65.2 \\
\hline & 16 & -775 & 3.55 & 1.62 & 71.8 \\
\hline & 18 & -760 & 4.74 & 2.16 & 62.4 \\
\hline & 20 & -725 & 5.60 & 2.56 & 55.5 \\
\hline & 22 & -745 & 6.49 & 2.96 & 48.5 \\
\hline \multirow{7}{*}{ PCBT } & 6 & -715 & 7.08 & 3.23 & 43.8 \\
\hline & 8 & -785 & 6.30 & 2.87 & 50.0 \\
\hline & 10 & -715 & 5.82 & 2.66 & 53.8 \\
\hline & 12 & -720 & 3.09 & 1.41 & 75.5 \\
\hline & 14 & -748 & 4.16 & 1.90 & 66.9 \\
\hline & 16 & -770 & 5.71 & 2.61 & 54.6 \\
\hline & 18 & -774 & 6.96 & 3.18 & 44.7 \\
\hline \multirow{8}{*}{$\mathrm{Zn}^{2+}$} & 30 & -655 & 6.02 & 2.75 & 52.2 \\
\hline & 45 & -690 & 5.62 & 2.56 & 55.4 \\
\hline & 60 & -750 & 4.26 & 1.94 & 66.2 \\
\hline & 75 & -705 & 3.98 & 1.81 & 68.4 \\
\hline & 90 & -740 & 4.16 & 1.90 & 66.9 \\
\hline & 105 & -740 & 4.78 & 2.18 & 62.0 \\
\hline & 120 & -690 & 5.25 & 2.39 & 58.3 \\
\hline & 30 & -655 & 6.02 & 2.75 & 52.2 \\
\hline
\end{tabular}

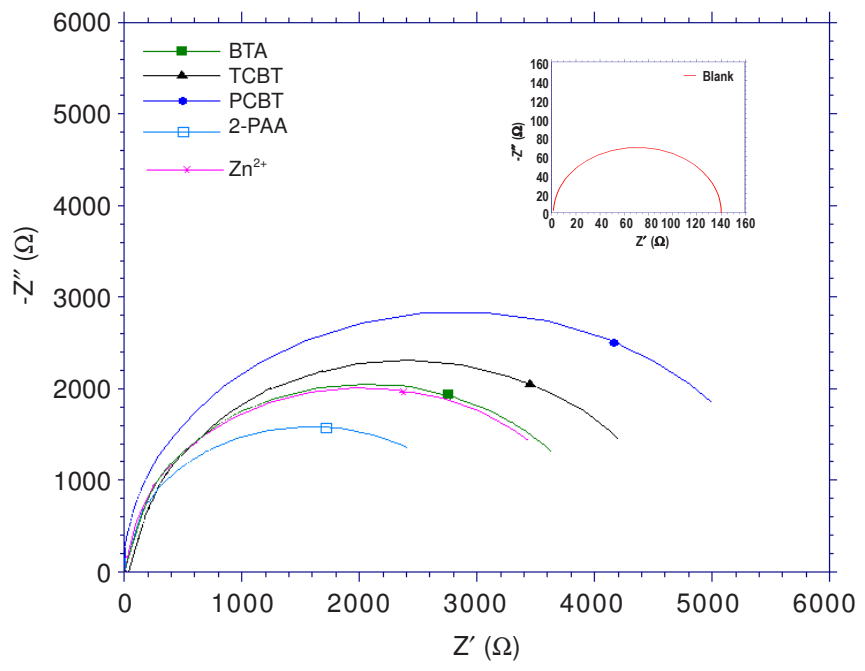

Fig. 4. Nyquist plot of mild steel in ground water in the presence and absence of optimum concentration of BTA, TCBT, PCBT, 2-PAA and $\mathrm{Zn}^{2+}$ 
TABLE-4

POTENTIODYNAMIC POLARIZATION PARAMETERS OF MILD STEEL IN GROUND WATER

CONTAINING OPTIMUM CONCENTRATION OF BINARY COMBINATION AND TERNARY

COMBINATION OF BENZOTRIAZOLE WITH PHOSPHONO DERIVATIVES AND Zn ${ }^{2+}$ AT $30^{\circ} \mathrm{C}$

\begin{tabular}{lccccc}
\multicolumn{1}{c}{ Inhibitor } & Inhibitor conc. $(\mathrm{ppm})$ & $\mathrm{E}_{\text {corr }}(\mathrm{mV})$ & $\mathrm{i}_{\text {corr }}\left(\mu \mathrm{A} \mathrm{cm} \mathrm{cm}^{-2}\right)$ & Corrosion rate $(\mathrm{mpy})$ & Inhibition efficiency $(\%)$ \\
\hline Blank & - & -640 & 12.59 & 5.75 & - \\
BTA + 2-PAA & $18+12$ & -625 & 3.52 & 1.61 & 72.0 \\
TCBT + 2-PAA & $16+12$ & -591 & 3.23 & 1.48 & 74.3 \\
PCBT + 2-PAA & $12+12$ & -568 & 2.73 & 1.25 & 78.3 \\
PCBT + Zn ${ }^{2+}+2-P A A$ & $12+75+12$ & -649 & 1.44 & 0.66 & 88.6 \\
\hline
\end{tabular}

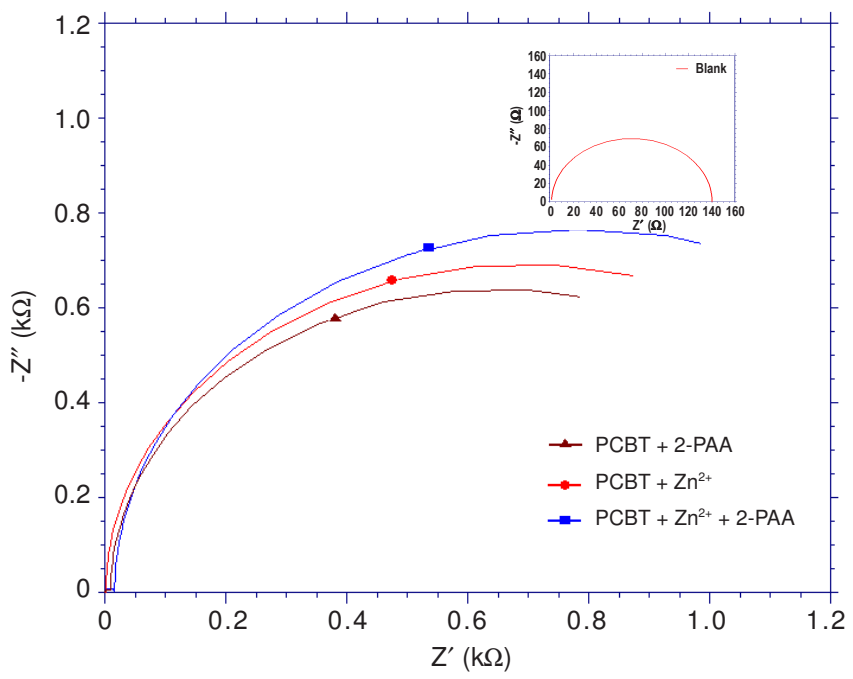

Fig. 5. Nyquist plot of mild steel in ground water in the absence and presence of optimum concentration of PCBT +2 -PAA, PCBT + $\mathrm{Zn}^{2+}$ and $\mathrm{PCBT}+\mathrm{Zn}^{2+}+2-\mathrm{PAA}$

different elements present in the equivalent circuit were evaluated using a fitting procedure and the parameters obtained are shown in Table-5.

\begin{tabular}{|c|c|c|c|}
\hline \multicolumn{4}{|c|}{$\begin{array}{c}\text { FOR MILD STEEL IN GROUND WATER IN THE } \\
\text { ABSENCE AND PRESENCE OF OPTIMUM } \\
\text { CONCENTRATION OF SIMPLE, BINARY AND } \\
\text { TERNARY COMBINATIONS OF BENZOTRIAZOLE, } \\
\text { PHOSPHONO DERIVATIVES AND Zn }{ }^{2+} \text { AT } 30^{\circ} \mathrm{C}\end{array}$} \\
\hline Inhibitor & $\begin{array}{c}\text { Inhibitor conc. } \\
(\mathrm{ppm})\end{array}$ & $\begin{array}{c}\mathrm{R}_{\mathrm{ct}} \times 10^{4} \\
(\Omega) \\
\end{array}$ & $\begin{array}{r}\mathrm{C}_{\mathrm{dl}} \\
(\mu \mathrm{F})\end{array}$ \\
\hline Blank & - & 0.0130 & 15.03 \\
\hline BTA & 18 & 0.4120 & 7.20 \\
\hline TCBT & 16 & 0.4549 & 7.05 \\
\hline PCBT & 12 & 0.5728 & 6.49 \\
\hline 2-PAA & 12 & 0.3168 & 7.83 \\
\hline $\mathrm{Zn}^{2+}$ & 75 & 0.3981 & 7.42 \\
\hline PCBT+2-PAA & $12+12$ & 1.2790 & 5.98 \\
\hline $\mathrm{PCBT}+\mathrm{Zn}^{2+}$ & $12+75$ & 1.2823 & 5.81 \\
\hline $\mathrm{PCBT}+\mathrm{Zn}^{2+}+2-\mathrm{PAA}$ & $12+75+12$ & 1.5316 & 3.53 \\
\hline
\end{tabular}

From the impedance plots of the individual inhibitors (2-PAA, BTA, TCBT, PCBT and $\mathrm{Zn}^{2+}$ ), it is evident that the values of charge transfer resistance increase in the order 2-PAA $<\mathrm{Zn}^{2+}<\mathrm{BTA}<\mathrm{TCBT}<\mathrm{PCBT}$, when compared to the blank while the capacitance values show an appreciable decrease in the reverse order. The combination of PCBT and $\mathrm{Zn}^{2+}$ a further increase in the charge transfer resistance is also noted and this value reaches a maximum for PCBT, $\mathrm{Zn}^{2+}$ and
2-PAA mixture $\left(1.5316 \times 10^{4} \Omega\right.$ at $\left.303 \mathrm{~K}\right)$, demonstrating that this combination provides the maximum corrosion protection. Increase of the charge transfer resistance and decrease of the double layer capacity with increasing inhibitor concentration indicate that these compounds inhibit the corrosion rate of mild steel by an adsorption mechanism ${ }^{21}$. When the temperature is increased the charge transfer resistance seems to be decreased significantly, at the same time the double layer capacitance was increased.

In fact, the presence of ternary system enhances the value of the charge transfer resistance in the aqueous medium and the effect being more pronounced with this combination. Also the values of double layer capacitance are brought down to the maximum extent in the presence of ternary systems, a sharp decrease is being more effective for the combination of PCBT $+\mathrm{Zn}^{2+}+2$-PAA. The decrease in $\mathrm{C}_{\mathrm{dl}}$ is due to the adsorption of this compound on the metal surface leading to the formation of a surface film in the aqueous solution ${ }^{22-24}$. All the AC measurements show the same trend as those observed from DC polarization.

Atomic absorption spectroscopic studies: The amount of iron leached-out to the ground water in the absence and presence of optimum concentration of ternary combinations of benzotriazole derivatives and phosphono derivatives along with $\mathrm{Zn}^{2+}$ were determined and presented in Fig. 6. The leachedout iron present in the solution was found to be $15.1 \mathrm{ppm}$. While, in the presence of inhibitor the leaching of iron was significantly decreased, it may be due to the adsorption of inhibitor molecules on the surface of mild steel and it prevents the dissolution of iron in the electrolyte. Among the studied individual inhibitor systems, PCBT was found to be very low dissolution of iron in the electrolyte (3.8 ppm). Among all the studied ternary combinations, the combinations of PCBT + $\mathrm{Zn}^{2+}+2$-PAA reduce the maximum extent of iron dissolution in the ground water medium due to its high inhibition efficiency and the concentration of iron in water was found to be $1.7 \mathrm{ppm}$.

\section{Conclusion}

The triazole derivatives (PCBT, TCBT and BTA), 2-PAA and $\mathrm{Zn}^{2+}$ showed good performance as corrosion inhibitors in more corrosive aqueous media. The benzotriazole and phosphono derivatives were found to suppress both cathodic and anodic reactions and hence behave as mixed type inhibitor. $\mathrm{PCBT}+\mathrm{Zn}^{2+}+2$-PAA formulation shows the highest inhibition efficiency. A good agreement was observed between weight loss measurements coupled with electrochemical measurements and AAS studies. 


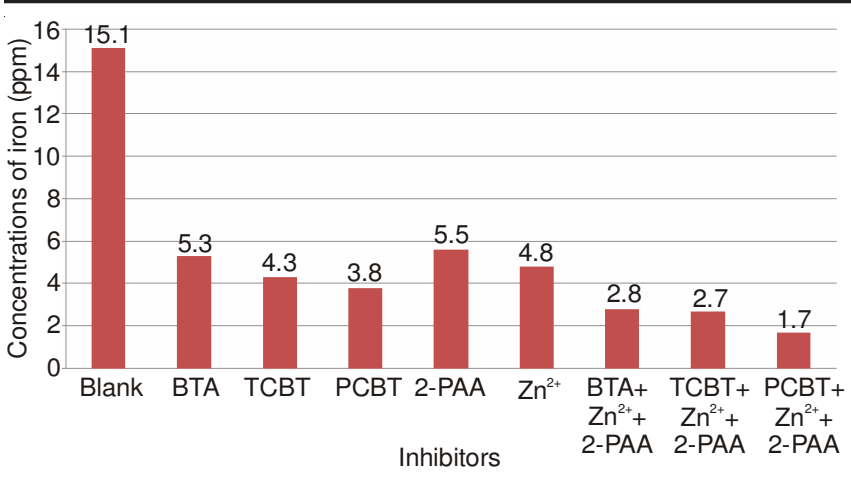

Fig. 6. Estimation of leached-out iron present in the absence and presence of optimum concentration of individual benzotriazole derivatives and benzotriazole derivatives with phosphono derivatives and $\mathrm{Zn}^{2+}$

\section{REFERENCES}

1. A.M. Alsabagh, M.A. Migahed and S.A. Hayam, Corros. Sci. 48, 813 (2006).

2. G. Trabanelli, Corrosion, 47, 410 (1991).

3. S.N. Raicheva, B.V. Aleksiev and E.I. Sokolova, Corros. Sci., 34, 343 (1993).

4. S. Arab and E.A. Noor, Corrosion, 49, 122 (1993).

5. M.A. Quraishi, M.A. Wajidkham and M. Ajmal, Bull. Electrochem. 11, 274 (1995).

6. A. Singh and R.S. Chaudhary, Br. Corros. J., 31, 300 (1996).
7. S.S. Abd El-Rehim, M.A.M. Ibrahim and K.F. Khalid, J. Appl. Electrochem., 29, 593 (1999).

8. M.A. Quraishi, R. Sardar and O. Jamal, Mater. Chem. Phys., 71, 309 (2001).

9. A. Yurt, A. Balaban, S.U. Kandemiv, G. Bereket and B. Erx, Mater. Chem. Phys., 85, 420 (2004).

10. H. Ashassi-Sorkhabi, B. Shaabani and D. Seifzadeh, Appl. Surf. Sci., 239, 154 (2005).

11. F. Bentiss, M. Traisnel, N. Chaibi, B. Mernari, H. Vezin and M. Lagrenée, Corros. Sci., 44, 2271 (2002).

12. S.S. Abd El-Rehim, S.A.M. Refaey, F. Taha, M.B. Saleh and R.A. Ahmed, J. Appl. Electrochem., 31, 429 (2001).

13. S. Tamil Selvi, V. Raman and N. Rajendran, J Appl Electrochem., 33, 1175 (2003).

14. E. Khamis, Corrosion, 46, 476 (1990).

15. E. Stupnisek-Lisac and M. Metikos-Hukovia, Br. Corr. J., 28, 74 (1993).

16. E. Stupnisek-Lisac and S. Podbrscek, J. Appl. Electrochem., 24, 779 (1994).

17. A.R. Katritzky, J. Org. Chem., 69, 6617 (2004).

18. X. Wang and Y. Zhang, Tetrahedron Lett., 59, 4201, (2003).

19. X. Wang and Y. Zhang, Tetrahedron Lett., 43, 5431, (2002).

20. F. Mansfeld, M.W. Kending and S. Tsai, Corros. Sci., 38, 570 (1982).

21. M.A. Quraishi and J. Rawat, Mater. Chem. Phys., 70, 95 (2001).

22. F. Bentiss, M. Lagrenee, M. Traisenl and J.C. Hornez, Corros. Sci., 41, 789 (1999).

23. D. Gopi, K.M. Govindaraju, V.C.A. Prakash, V. Manivannan and L. Kavitha, J. Appl. Electrochem., 39, 269 (2009).

24. D. Gopi, K.M. Govindaraju, V.C.A. Prakash, D.M. Angeline Sakila and L. Kavitha, Corros. Sci., 51, 2259 (2009). 